\title{
The Eocene South American metatherian Zeusdelphys complicatus is not a protodidelphidid but a hatcheriform: Paleobiogeographic implications
}

\author{
Leonardo M. Carneiro and Édison Vicente Oliveira \\ Acta Palaeontologica Polonica 62 (3), 2017: 497-507 doi:https://doi.org/10.4202/app.00351.2017
}

Zeusdelphys complicatus is one of the most enigmatic metatherians from the Itaboraí Basin.

The type and only known specimen was previously regarded as the upper dentition of Eobrasilia; an M4 of a new taxon; an M3 of a Kollpaniidae (now regarded as a group of "condylarths"); a probable M1 of an incertae sedis taxon; and as an M1 of a

Protodidelphidae. Herein, we present a morphological review of the dental structures of Zeusdelphys complicatus, presenting new interpretations and comparing it with other North and South

American taxa. We also perform a phylogenetic analysis in order to test the affinities of Zeusdelphys and the validity of most studied characters. The results recovered Zeusdelphys complicatus as more closely related to Hatcheritherium alpha than to any other metatherian.

Glasbiidae were recovered as the sister lineage of Protodidelphidae within

Didelphimorphia, as true marsupials. Ectocentrocristus was recovered as the sister taxon of Zeusdelphys + Hatcheritherium, as a Hatcheriformes. The analysis recovered this suborder as an independent lineage from Polydolopimorphia, being more closely related to

"Alphadontidae". The affinities with Protodidelphidae are a result of convergent evolution, as Zeusdelphys is more closely related to Hatcheritherium alpha from the Late Cretaceous of North America. The results support a North American origin for Hatcheriformes. The presence of strong sea-level lowstands and islands in the Caribbean Plate during the Late Cretaceous provide valid data to support a faunal interchange between Americas during the latest Late Cretaceous. Based on the results, Zeusdelphys represents a South American early Eocene surviving Hatcheriformes.

Key words: Mammalia, Metatheria, Hatcheriformes, Zeusdelphys, paleobiogeography, systematics, Eocene, Itaboraí Basin.

Leonardo M. Carneiro [leonardo.carneiro8@gmail.com], PALEOLAB (Laboratório de Paleontologia), Departamento de Geologia, Centro de Tecnologia e Geociências, Universidade Federal de Pernambuco, UFPE, Av. Acadêmico Hélio Ramos s/n, CEP 50740-530, Recife, PE, Brazil, and Laboratório de Paleontologia e Paleoecologia da Sociedade de História Natural, Travessa Florêncio Augusto Chagas nº 8B, 2560-230 Torres Vedras, Portugal. 
Édison Vicente Oliveira [vicenteedi@gmail.com], PALEOLAB (Laboratório de Paleontologia), Departamento de Geologia, Centro de Tecnologia e Geociências, Universidade Federal de Pernambuco, UFPE, Av. Acadêmico Hélio Ramos s/n, CEP 50740-530, Recife, PE, Brazil.

This is an open-access article distributed under the terms of the Creative Commons Attribution License (for details please see creativecommons.org), which permits unrestricted use, distribution, and reproduction in any medium, provided the original author and source are credited.

FoF Full text $(242.2 \mathrm{kB})$ 